Frédéric van den Brûle $\cdot$ Crina Buicu • Jacques Dequesne • Philippe Herman • Ulysse J. Gaspard

\title{
Treatment of peroperative hemorrage during operative hysteroscopy using bipolar energy with intrauterine tranexamic acid: a case report
}

Published online: 11 May 2004

(C) Springer-Verlag Berlin / Heidelberg 2004

\begin{abstract}
Operative hysteroscopy is an efficient alternative treatment of leiomyoma-associated menorrhagia. This manuscript describes a typical case of uterine leiomyoma that was treated using a bipolar resectoscope and saline as a distension medium. This allowed completion of a difficult resection with a lower risk of hemodilution and hyponatremia, compared to the use of a monopolar resectoscope with glycine as a distension fluid. Moreover, we describe an original treatment of peroperative uterine bleeding using intrauterine instillation of tranexamic acid through a Foley catheter.
\end{abstract}

Keywords Operative hysteroscopy · Bipolar energy · TURP syndrome $\cdot$ Bleeding $\cdot$ Tranexamic acid

\section{Introduction}

Abnormal uterine bleeding constitutes a frequent problem in gynecology. Many of these patients present with uterine leiomyoma, which are often a cause for hysterectomy $[1,2]$. Transcervical resection of the endometrium and of the myomas, performed by operative hysteroscopy, has been demonstrated to be an efficient $[3,4,5,6]$ and costeffective alternative in the treatment of these disorders [7, 8]. However, the efficacy of this technique is limited in large uteri with numerous leiomyomas [2, 8].

Preoperative treatment of large leiomyoma using $\mathrm{GnRH}$ agonists has been advocated $[9,10,11]$, but the cost-effi-

\author{
F. van den Brûle ( $)$ C. Buicu · J. Dequesne · P. Herman · \\ U. J. Gaspard \\ Department of Gynecology, \\ CHU B35 Sart Tilman, \\ 4000 Liège, Belgium \\ e-mail: f.vandenbrule@chu.ulg.ac.be \\ Tel.: +32-4-3667169 \\ Fax: +32-4-3668266

\section{J. Dequesne} \\ Department of Gynecology, \\ Clinic Cecil,
}

1007 Lausanne, Switzerland cacy ratio of this strategy has been discussed [12]. Use of glycine as a distension medium with this technique is associated with risks of fluid overload, hypoosmolality and hyponatriemia, first described as the transuretral resection of the prostate (TURP) syndrome $[13,14,15,16,17,18$, 19]. This constitutes a risk of potentially fatal hyponatremic encephalopathy [20]. Recently, bipolar resectoscopes have been developed [21]. These devices allow the use of saline as a distension medium, which reduces the risk of fluid overload compared to glycine. Transcervical resection of intracavitary leiomyoma can be the source of peroperative bleeding by opening of radial veins around the myomas [3]. This event can be handled by careful coagulation of these veins and systemic use of antifibrinolytic agents such as tranexamic acid [22].

In this paper, we describe the case of a patient who underwent transcervical resection of the endometrium and of submucous leiomyoma using a bipolar resectoscope whose peroperative uterine bleeding was controlled by intrauterine instillation of tranexamic acid.

\section{Case report}

Mrs D.D., aged 50 years, para 1, complained of regular menorrhagia with abundant blood clots occurring approximately 910 days every month. She previously had been diagnosed with sideropenic anemia and was prescribed oral iron supplementation. A previous trial of medical treatment using nomegestrol acetate (Lutenyl) was only transiently efficacious to reduce menorrhagia. Her medical history was uneventful.

The clinical examination revealed type- 2 cystocele. Pap smears were negative. Vaginal examination showed an enlarged uterus. Transvaginal sonography highlighted an enlarged anteverted uterus $(97 \times 77 \times 85 \mathrm{~mm})$ with multiple intramyometrial leiomyomas (diameter from 7 to $30 \mathrm{~mm}$ ). Three posterior myomas were submucous (classification of the European Society for Gynecological Endoscopy, type 1 and 2), with diameters ranging from 15 to $35 \mathrm{~mm}$.

Hysterectomy and correction of the cystocele were proposed to the patient, but she refused this surgical alternative. Operative hysteroscopy was then proposed. The patient was informed that this was a borderline indication because of the large size of the uterus and the numerous leiomyomas. However, she chose the latter surgical option. Preoperative chest X-ray and electrocardiogram were normal. 
Operative hysteroscopy was performed using a 9-mm (27-Fr) double-flow, bipolar Versapoint resectoscope using the loop electrode (Johnson \& Johnson Medical, Gynecare, Dilbeek, Belgium) under rachianesthesia. Dilatation was progressively performed using Hegar dilatators to $10 \mathrm{~mm}$. Sterile saline was used as the distension medium. Fluid balance was monitored using an Uteromat system (Olympus, Omnilabo, Aartselaar, Belgium). Intrauterine pressure was set at $130 \mathrm{~mm} \mathrm{Hg}$, and the flow rate at $350 \mathrm{ml} / \mathrm{min}$. A hysteroscopic view of the uterine cavity confirmed the presence of the two posterior submucous leiomyomas (diameters of 40 and $25 \mathrm{~mm}$ ) and of another $25 \mathrm{~mm}$ submucous myoma located on the right side of the cavity. Resection of the leiomyomas and of the endometrium was carried out using the bipolar loop of the resectoscope. The total resection volume was $20 \mathrm{cc}$, and the operative time was $80 \mathrm{~min}$. A total of 2.11 of saline was used. Monitoring of the fluid balance revealed a loss of $500 \mathrm{ml}$. The end of the procedure was characterized by abundant intrauterine bleeding, not easily controlled by the resectoscope. At this very moment, the patient reported intense pain in the cubital side of the left arm and the left side of the mandibula. Heart monitoring showed a slightly lowered ST segment, suggestive of coronary heart disease, which precluded systemic administration of tranexamic acid for the peroperative bleeding. After discussion with the anesthesist, we decided to administer tranexamic acid in loco and introduced a Foley catheter inside the uterus, inflated the balloon and injected two vials of $500 \mathrm{mg}$ tranexamic acid inside the uterine cavity. The drug was left in place for $2 \mathrm{~h}$, then the catheter was removed. No uterine bleeding was observed. Blood testing 1 and $6 \mathrm{~h}$ after the procedure showed slight hemodilution (serum proteins, 61 and $54 \mathrm{~g} / 1$, normal range 66-83; albumin $30 \mathrm{~g} / \mathrm{l}$, normal range 38-49) without perturbation of the ions. At $6 \mathrm{~h}$ postoperatively, D-dimers were increased at $386 \mu \mathrm{g} / \mathrm{l}$ (normal, <200), suggesting that tranexamic acid only had local inhibitory effect on fibrinolysis. Total and MB-type creatine kinase and $\mathrm{T}$ troponin were in the normal range. Cardiological examination and electrocardiography were negative.

Postoperative follow-up was uneventful, and the patient was discharged the day after the procedure. Pathological examination of the resected endometrial chips confirmed the diagnosis of uterine leiomyoma and of irregularly developed endometrium, with both proliferative and secretory endometrial glands. Postoperative control was performed 8 weeks after hysteroscopy. The patient did not experience any abnormal uterine bleeding.

\section{Discussion}

This case constitutes a good example of the use of conservative hysteroscopic surgery for the treatment of menorrhagia associated with uterine leiomyomatosis [3, 4]. The patient refused hysterectomy. Operative hysteroscopy using a monopolar hysteroscope and glycine as a distention medium was not an adequate choice because of the size of the uterus and the numerous leiomyoma, hence the risk of fluid overload and hyponatremia. Thus, a bipolar resectoscope and saline as a distention fluid were used. The procedure was difficult, with peroperative uterine bleeding. Intravenous tranexamic acid was not administrated as the patient presented with signs suggestive of coronary heart disease. We thus decided to instill tranexamic acid where it should be active, i.e., in the uterus. Although this clinical history does not constitute a proof for the efficacy of this strategy, it could certainly be remembered as an alternative treatment of peroperative bleeding.

Aknowledgements The authors thank Johnson \& Johnson Belgium and Mrs. Nathalie Doms (Johnson \& Johnson Belgium) for providing the Versapoint resectoscope. The authors also thank Olym- pus Belgium (Aartselaar, Belgium) for continuous support. We also thank Dr. J.-L. David for fruitful discussions concerning the mechanisms of hemostasis.

\section{References}

1. Lefebvre G, Allaire C, Jeffrey J, Vilos G, Arneja J, Birch C, et al (2002) SOGC clinical guidelines. Hysterectomy. J Obstet Gynaecol Can 24:37-61; quiz 74-76

2. Lefebvre G, Vilos G, Allaire C, Jeffrey J, Arneja J, Birch C, et al (2003) The management of uterine leiomyomas. J Obstet Gynaecol Can 25:396-418; quiz 419-422

3. Brandner P, Neis KJ, Diebold P (2000) Hysteroscopic resection of submucous myomas. Contrib Gynecol Obstet 20:81-90

4. Lethaby A, Shepperd S, Cooke I, Farquhar C (2000) Endometrial resection and ablation versus hysterectomy for heavy menstrual bleeding. Cochrane Database Syst Rev 2:CD000329

5. Lethaby A, Hickey M (2002) Endometrial destruction techniques for heavy menstrual bleeding: a Cochrane review. Hum Reprod 11:2795-2806

6. Lethaby A, Hickey M (2002) Endometrial destruction techniques for heavy menstrual bleeding. Cochrane Database Syst Rev 2:CD001501

7. Hidlebaugh DA (2000) Cost and quality-of-life issues associated with different surgical therapies for the treatment of abnormal uterine bleeding. Obstet Gynecol Clin North Am 27:451-65

8. Ravi B, Schiavello H, Chandra P, Takeshige T (2001) Safety and efficacy of hysteroscopic endomyometrial resection-ablation for menorrhagia. J Reprod Med 46:717-723

9. Lethaby A, Vollenhoven B, Sowter M (2000) Pre-operative GnRH analogue therapy before hysterectomy or myomectomy for uterine fibroids. Cochrane Database Syst Rev 2:CD000547

10. Lethaby A, Vollenhoven B, Sowter M (2001) Pre-operative GnRH analogue therapy before hysterectomy or myomectomy for uterine fibroids. Cochrane Database Syst Rev 2:CD000547

11. Lethaby A, Vollenhoven B, Sowter M (2002) Efficacy of preoperative gonadotrophin hormone releasing analogues for women with uterine fibroids undergoing hysterectomy or myomectomy: a systematic review. BJOG 109:1097-108

12. Farquhar C, Brown PM, Furness S (2002) Cost effectiveness of pre-operative gonadotrophin releasing analogues for women with uterine fibroids undergoing hysterectomy or myomectomy. BJOG 109:1273-1280

13. Istre O, Skajaa K, Schjoensby AP, Forman A (1992) Changes in serum electrolytes after transcervical resection of endometrium and submucous fibroids with use of glycine $1.5 \%$ for uterine irrigation. Obstet Gynecol 80:218-222

14. Witz CA, Silverberg KM, Burns WN, Schenken RS, Olive DL (1993) Complications associated with the absorption of hysteroscopic fluid media. Fertil Steril 60:745-756

15. Loffer FD (1995) Contraindications and complications of hysteroscopy. Obstet Gynecol Clin North Am 22:445-455

16. Loffer FD (1995) Complications of hysteroscopy-their cause, prevention, and correction. J Am Assoc Gynecol Laparosc 3:11-26

17. Cooper JM, Brady RM (2000) Intraoperative and early postoperative complications of operative hysteroscopy. Obstet Gynecol Clin North Am 27:347-366

18. Bradley LD (2002) Complications in hysteroscopy: prevention, treatment and legal risk. Curr Opin Obstet Gynecol 14:409-415

19. Mushambi MC, Williamson K (2002) Anaesthetic considerations for hysteroscopic surgery. Best Pract Res Clin Anaesthesiol 16:35-52

20. Arieff AI, Ayus JC (2000) Endometrial ablation complicated by fatal hyponatremic encephalopathy. JAMA 270:1230-1232

21. Brill AI (2000) Energy systems for operative hysteroscopy. Obstet Gynecol Clin North Am 27:317-326

22. Oehler MK, Rees MC (2003) Menorrhagia: an update. Acta Obstet Gynecol Scand 82:405-422 